\title{
CONTINUITY PROPERTIES FOR RIESZ POTENTIALS OF FUNCTIONS IN MORREY SPACES OF VARIABLE EXPONENT
}

\author{
Yoshiniro MizUTA AND TETSU SHIMOMURA
}

Abstract. Our aim in this paper is to deal with continuity properties for Riesz potentials of functions in Morrey spaces of variable exponent. The modulus of continuity is determined by the structure of Morrey space.

Mathematics subject classification (2010): 31B15, 46E35.

Keywords and phrases: Continuity of Riesz potentials, Sobolev's embedding theorem, Morrey spaces of variable exponent.

\section{REFERENCES}

[1] D. R. ADAMS, A note on Riesz potentials, Duke Math. J. 42 (1975), 765-778.

[2] T. Futamura AND Y. MizutA, Continuity properties of Riesz potentials for functions in $L^{p(\cdot)}$ of variable exponent, Math Inequal. Appl. 8(4) (2005), 619-631.

[3] T. Futamura, Y. Mizuta And T. Shimomura, Sobolev embeddings for Riesz potential spaces of variable exponent, Math. Nachr. 279 (2006), 1463-1473.

[4] T. FUtAMURA, Y. MiZUTA AND T. SHIMOMURA, Sobolev embeddings for Riesz potential space of variable exponent on metric spaces, Ann. Acad. Sci. Fenn. Math. 31 (2006), 495-522.

[5] P. HARJUlehto AND P. HÄstÖ, A capacity approach to the Poincaré inequality and Sobolev imbeddings in variable exponent Sobolev spaces, Rev. Mat. Complut. 17 (2004), 129-146.

[6] L. I. HedBerG, On certain convolution inequalities, Proc. Amer. Math. Soc. 36 (1972), 505-510.

[7] O. KovÁČIK AND J. RÁKOSNÍK, On spaces $L^{p(x)}$ and $W^{k, p(x)}$, Czechoslovak Math. J. 41 (1991), 592-618.

[8] Y. MizuTA, Potential theory in Euclidean spaces, Gakkōtosyo, Tokyo, 1996.

[9] Y. MIZUTA, Continuity properties of Riesz potentials and boundary limits of Beppo Levi functions, Math. Scand. 63 (1988), 238-260.

[10] Y. MizuTA, Continuity properties of potentials and Beppo-Levi-Deny functions, Hiroshima Math. J. 23 (1993), 79-153.

[11] Y. MizuTA AND T. SHimomuRA, Differentiability and Hölder continuity of Riesz potentials of functions in Orlicz classes, Analysis 20 (2000), 201-223.

[12] Y. MizUTA AND T. SHIMOMURA, Sobolev embeddings for Riesz potentials of functions in Morrey spaces of variable exponent, J. Math. Soc. Japan 60 (2008), 583-602.

[13] E. NAKAI, Generalized fractional integrals on Orlicz-Morrey spaces, Banach and function spaces, 323-333, Yokohama Publ., Yokohama, 2004.

[14] W. ORLICZ, Über konjugierte Exponentenfolgen, Studia Math. 3 (1931), 200-211.

[15] J. PEETRE, On the theory of $L_{p, \lambda}$ spaces, J. Funct. Anal. 4 (1969), 71-87.

[16] M. RŮŽIČKA, Electrorheological fluids: modeling and Mathematical theory, Lecture Notes in Math. 1748, Springer, Berlin, 2000.

[17] Y. SAWANo and H. TANaKa, Morrey spaces for non-doubling measures, Acta Math. Sin. (Engl. Ser.) 21 (2005), 1535-1544. 